\title{
Studies on the effect of ethanolic extract of propolis in BALB/c mice
}

\author{
Preeti Kalia $^{1 *}$, Neelima R. Kumar ${ }^{1}$ and Kusum Harjai ${ }^{2}$ \\ ${ }^{1}$ Department of Zoology, Panjab University, Chandigarh, INDIA \\ ${ }^{2}$ Department of Microbiology, Panjab University, Chandigarh, INDIA \\ *Corresponding author. E-mail: preeti.kalia84@gmail.com
}

Received: August 21, 2014; Revised received: September 25, 2014; Accepted: November 11, 2014

Abstract: Propolis is widely used since ages for the treatment of various ailments. Present study focussed on the toxicity profile of ethanolic extract of propolis on BALB/c mice. The effect of different concentrations of propolis (300, $500,1000 \mathrm{mg} / \mathrm{kg}$ body weight) was analysed by studying the biochemical, haematological and histological changes in mice for 28 days. No significant difference in various parameters were observed in groups of mice treated with propolis and the normal control $(p>0.05)$. Histological findings on liver, spleen, kidney and brain revealed normal architecture. The ethanolic extract of propolis did not produce significant toxic effect in mice and hence can be utilized for nutraceuticals formulations.

Keywords: Biochemical, Histological, Propolis, Toxicology

\section{INTRODUCTION}

Natural products are once again being tested, tried and promoted for their beneficial and or therapeutic properties. The use of honey bee products is encouraged these days and branch which deals with the medicinal use of bee products is known as Apitherapy. Various medicinal properties of bee products like honey, pollen, propolis (Kalia et al. 2013 and Singla et $a l ., 2014)$, royal jelly, bee venom has been extensively studied now a days. These products are made by honey bees itself (bee wax) or are collected from different plants (propolis and pollen) then further modified the collected plant products (Kaur and Kumar 2013a). Propolis is a resinous natural product which honey bees collect from tree barks, buds and mix it with wax and bee secretions (Drago et al., 2007). The word 'pro-polis' is derived from the Greek pro- for or in defense and polis- the city, that is, defence of the city (or the hive) (Ghisalberti, 1979). Honey bees use this as a sealant in the hive, to fill the cracks, smoothing of internal walls and to protect the bee hive from the attack of microorganisms.

Propolis is a lipophilic material hard and brittle when cold but soft, pliable and sticky when warm, hence the name bee glue (Hausen et al., 1987). The composition of propolis depends upon various factors like-geographical origin, plant source and the season of collection. In general, it is composed of $50 \%$ resin and vegetable balsam, 30\% wax, $10 \%$ essential and aromatic oils, $5 \%$ pollen and $5 \%$ various other substances, including organic debris as studied by various researchers (Cirasino et al., 1987, Monti et al.,
1983). It has traditionally been used as an emollient and recent investigations have pointed towards its antibiotic properties ( Mirzova et al., 1997; Hendi et al., 2011). However the adverse effects that natural products can have, are sometimes ignored. These may cause allergy, dizziness, vomiting, fast heart beat, ulcer and even death (Gessler, 1995).In order to minimize these side effects, it is necessary that with the knowledge and facilities now available, the toxicological effects of natural products should be investigated before putting these to various uses.. The aim of present study was to analyze if there was any toxic impact of propolis consumption on mice by working on different parameters of biochemistry, haematology and histology.

\section{MATERIALS AND METHODS}

Collection of propolis and preparation of extracts: Propolis was obtained by scraping it off from the honey bee hives kept in an apiary maintained by Department of Zoology, Panjab University, Chandigarh, India. Ethanolic extract was prepared by following standard protocol (Kalia et al., 2013). The sample (10 g) was cut into small pieces ground and subsequent solvent extraction was done using the solvent ethanol. The volume was made to $40 \mathrm{ml}$ and it was kept for 5 days with occasional shaking. It was filtered through a Whatman \# 41 filter paper and then dried for further use.

Experimental design: BALB/c Male mice weighing 20-25g were used for the present study. Mice were obtained from Central Animal House, Panjab University. All the animals were housed in 
polypropylene cages and fed with a standard pellet diet (Ashirwad industries, Punjab, Hindustan lever, India) and water ad libitum. The treatment of the mice was according to the guidelines of the committee for the purpose of control and supervision of experiments on animals and approved by Panjab University Ethics Committee.

Acute toxicity study: World Health Organization guidelines (WHO, 2000) and Organization for economic cooperation development guidelines (OECD), 2002 were followed for evaluating acute oral toxicity. Treated mice were given the propolis extract at doses of 1,3 and $5 \mathrm{~g} / \mathrm{kg}$ body weight and then observed for 14 days while normal control group received water. All mice were observed for signs of toxicity during the experimental period.

Sub acute toxicity: The sub acute toxicity was evaluated following WHO guidelines of WHO (2000) and OECD ( 2008). Mice were divided into different groups. Treated groups were orally given different doses i.e. 300,500 and $1000 \mathrm{mg} / \mathrm{kg}$ body weight for 28 days. The control group received only water. Mice were observed for toxic signs.

Collection of blood and tissue: The mice were lightly anaesthetized with di-ethyl ether. Blood was drawn from jugular vein for biochemical and hematological investigations. After blood collection mice were sacrificed and organs like liver, spleen, kidney and brain were removed aseptically.

Biochemical studies: The collected blood was allowed to stand for 30 minutes and then centrifuged to obtain the serum. The serum was used for analysis of various liver function tests like SGOT, SGPT, alkaline phosphatase, bilirubin, urea, uric acid and creatinine by using standard kits (Avecon ) and analysis of blood glucose, proteins was also performed by using standard kits (Erba Diagnostic kits).
Haematological studies: Blood for haematology was collected in Ethylenediaminetetraacetic acid (EDTA) coated vials and examined for RBC count, WBC count, Haemogloblin, Packed cell volume (PCV) by standard protocols (Jain,1986).

Histopathological studies: After sacrifice, the organs (liver, spleen, kidney and brain) were fixed in $10 \%$ formalin and subjected to histological procedures. Histological processing included dehydrating, paraffin embedding, block making, section cutting, staining with hematoxlin and eosin and finally mounting by the method of Baker (1945).

Statistical analysis: All the values were expressed as Mean \pm Standard deviation. Statistical differences between the various groups were evaluated by ANOVA (Sigma plot) . p-values $<0.05$ were considered significant.

\section{RESULTS}

Weekly changes in the body weight were observed. The body weight increased but not with a significant difference in all groups except in P1000 where highly significant $\quad(\mathrm{p}<0.001)$ increase in body weight of mice was observed (Fig. 1). Mice treated with different doses of propolis neither showed any signs of toxicity nor any death of mice occurred during 14 days of the study. This suggested that the toxic dose of propolis should be more than $5 \mathrm{~g} /$ $\mathrm{kg}$ body weight. Similarly the sub - acute toxicity studies of propolis did not reveal any toxic symptoms. No significant difference was observed in propolis treated groups when compared with normal control.

The effect of ethanolic extract of propolis on various biochemical enzymes of mice after 28 days of treatment was evaluated and is presented in Table 1. EEP did not significantly alter the liver function enzymes levels i.e. SGOT, alkaline phosphatase as compared to normal control. The

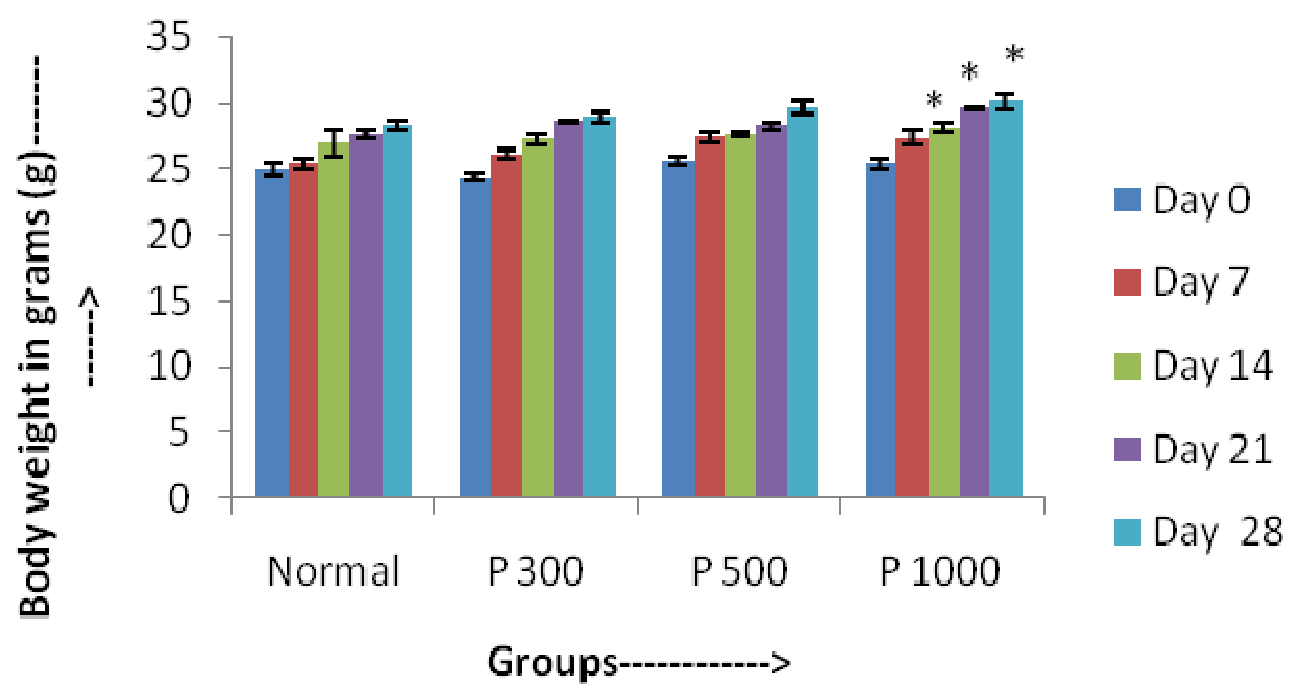

Fig.1. Histogram showing weekly changes in body weight of different groups of mice. *: Significant ( $p<0.001)$, 
Table 1. Effect of propolis on biochemical markers of normal and propolis treated mice.

\begin{tabular}{lcccc}
\hline Parameters & Control & $\mathbf{3 0 0} \mathbf{m g} / \mathbf{k g ~ b w}$ & $\mathbf{5 0 0 m g / k g ~ b w}$ & $\mathbf{1 0 0 0 m g / k g ~ b w}$ \\
\hline SGOT (IU/L) & $25.97 \pm 1.04$ & $35.43 \pm 4.9$ & $30.7 \pm 4.6$ & $25.33 \pm 0.57$ \\
SGPT (IU/L) & $21.4 \pm 0.87$ & $19.66 \pm 0.57 *$ & $20.33 \pm 0.57$ & $21 \pm 1$ \\
Alkaline phosphatase & $8.57 \pm 0.73$ & $7.66 \pm 0.5$ & $8.33 \pm 0.5$ & $8.77 \pm 0.51$ \\
(KA units) & & & \\
Bilirubin (mg/dL) & $0.85 \pm 0.12$ & $0.74 \pm 0.04 *$ & $0.7 \pm 0.06$ & $0.86 \pm 0.11$ \\
Urea (mg/dL) & $43.26 \pm 0.9$ & $43.86 \pm 1.62$ & $42.3 \pm 1.95$ & $42.3 \pm 1.9$ \\
Uric Acid (mg/dL) & $3.033 \pm 0.2$ & $3 \pm 0.1$ & $3.86 \pm 0.35$ & $2.93 \pm 0.11$ \\
Creatinine (mg/dL) & $0.38 \pm 0.056$ & $0.3 \pm 0.02$ & $0.4 \pm 0.011$ & $0.31 \pm 0.02$ \\
Glucose (mg/dL) & $133.33 \pm 6.67$ & $135.55 \pm 3.85$ & $131.1 \pm 3.85$ & $135.55 \pm 7.7$ \\
Protein (g/dL) & $6.933 \pm 0.23$ & $6.533 \pm 0.23$ & $6.66 \pm 0.46$ & $7.06 \pm 0.23$ \\
\hline
\end{tabular}

$p>0.05:$ non significant, $* p<0.05:$ Significant

Table 2: Effect of Ethanolic extract of propolis on various haematological parameters.

\begin{tabular}{lcccc}
\hline Parameters & Control & $\mathbf{3 0 0} \mathbf{m g} / \mathbf{k g ~ b w}$ & $\mathbf{5 0 0} \mathbf{~ m g} / \mathbf{k g ~ b w}$ & $\mathbf{1 0 0 0 m g / k g ~ b w}$ \\
\hline RBC $\left(\mathrm{million} / \mathrm{mm}^{3}\right)$ & $8.36 \pm 1.2$ & $8.06 \pm 0.66$ & $7.13 \pm 0.55^{*}$ & $7.5 \pm 0.7$ \\
$\mathrm{Hb}(\mathrm{g} / \mathrm{dl})$ & $13.23 \pm 1.26$ & $12.6 \pm 0.55$ & $11.66 \pm 0.57 *$ & $12.83 \pm 0.76$ \\
PCV $(\%)$ & $42 \pm 1$ & $44 \pm 1.73$ & $38.6 \pm 0.96^{*}$ & $40.33 \pm 0.75$ \\
MCV $(\mu \mathrm{m} 3)$ & $48.33 \pm 3.85$ & $53.49 \pm 3.79$ & $54.29 \pm 3$ & $53.86 \pm 4.28$ \\
MCH (pg) & $13.68 \pm 1.88$ & $14.82 \pm 1.23$ & $12.4 \pm 0.34$ & $12.4 \pm 0.34$ \\
MCHC $(\%)$ & $29.27 \pm 0.82$ & $28.68 \pm 1.35$ & $33.26 \pm 2.75$ & $28.93 \pm 1.84$ \\
WBC (per mm $\left.{ }^{3}\right)$ & $7730 \pm 170.88$ & $7348.33 \pm 47.52^{*}$ & $7418.33 \pm 114.05$ & $7538.33 \pm 25.65$ \\
Neutrophiles $(\%)$ & $20.83 \pm 1.44$ & $19.33 \pm 0.57 *$ & $19.83 \pm 0.28$ & $20.33 \pm 0.57$ \\
Lymphocytes(\%) & $69.19 \pm 1.44$ & $71.66 \pm 1.44 *$ & $70.83 \pm 0.76$ & $69.66 \pm 0.57$ \\
Eosinophiles $(\%)$ & $1 \pm 0$ & $1.16 \pm 0.28$ & $0.83 \pm 0.28$ & $1 \pm 0.5$ \\
Monocytes $(\%)$ & $1.66 \pm 0.28$ & $1.83 \pm 0.28$ & $2 \pm 0$ & $1.33 \pm 0.28$ \\
\hline
\end{tabular}

$p>0.05:$ non significant, $* p<0.05:$ Significant

kidney marker molecules like urea, uric acid, creatinine, were also not changed when compared to normal control $(p>0.05)$. The results showed that propolis did not hamper the activity of the vital functions (Table1).

Propolis extract did not alter the levels of blood parameters like RBC count, HB, PCV, MCV, MCH, WBC count (Table 2). Though the number of RBC's, and $\mathrm{Hb}$ level was reduced in one of the propolis treated group yet the values were within the normal range.

Histology of all organs i.e. liver, spleen, kidney and brain showed the same histoarchitecture in the normal and propolis treated groups indicating neutrality of propolis towards theses organs as shown in photomicrographs (Fig.1). The transverse section of normal liver showed hepatic lobules consisting of large polygonal cells, the hepatocytes, with prominent round nuclei and eosinophilic cytoplasm arranged radially around the central vein (A). The histology of liver of mice treated with propolis revealed regular hepatic details. Polyhedral hepatocytes were radiating outwards from central vein. No disturbance was seen in portal triad. Sinusoidal spaces were normal. No lymphocytic infilteration was observed (B). Spleen showed white, red pulp regions and marginal zone without any abnormality in normal (C) and propolis treated mice (D). Histological examination of normal (E)and propolis $(\mathrm{F})$ treated mice kidney revealed the same typical organization with outer cortex and inner medulla region. Similarly, the histology of mouse brain appeared normal showing cerebellum and cerebral cortex regions with no signs of meningitis in both normal and propolis treated mice $(\mathrm{G}-\mathrm{H})$.

\section{DISCUSSION}

The acute toxicity study showed that the $\mathrm{LD}_{50}$ of ethanolic extract of propolis was more than $5 \mathrm{~g} / \mathrm{kg}$ body weight of mice. These results suggested that EEP has high safety margin since the mice tolerated upto $5 \mathrm{~g} / \mathrm{kg}$ bw of extract orally. Arvouet- Grand et al. (1993) had reported the oral $\mathrm{LD}_{50}$ of propolis in mouse to be greater than $7340 \mathrm{mg} / \mathrm{kg}$ body weight The crude ethanolic extract of propolis was assigned as class 5 $\left(\mathrm{LD}_{50}>2000 \mathrm{mg} / \mathrm{kg}\right)$, that is the lowest toxicity class according to chemical labeling and classification of acute systemic toxicity (OECD, 2002).

In case of sub acute toxicity studies, no change in body weight was observed in propolis treated mice and normal control group. Similarly, the gross examination 

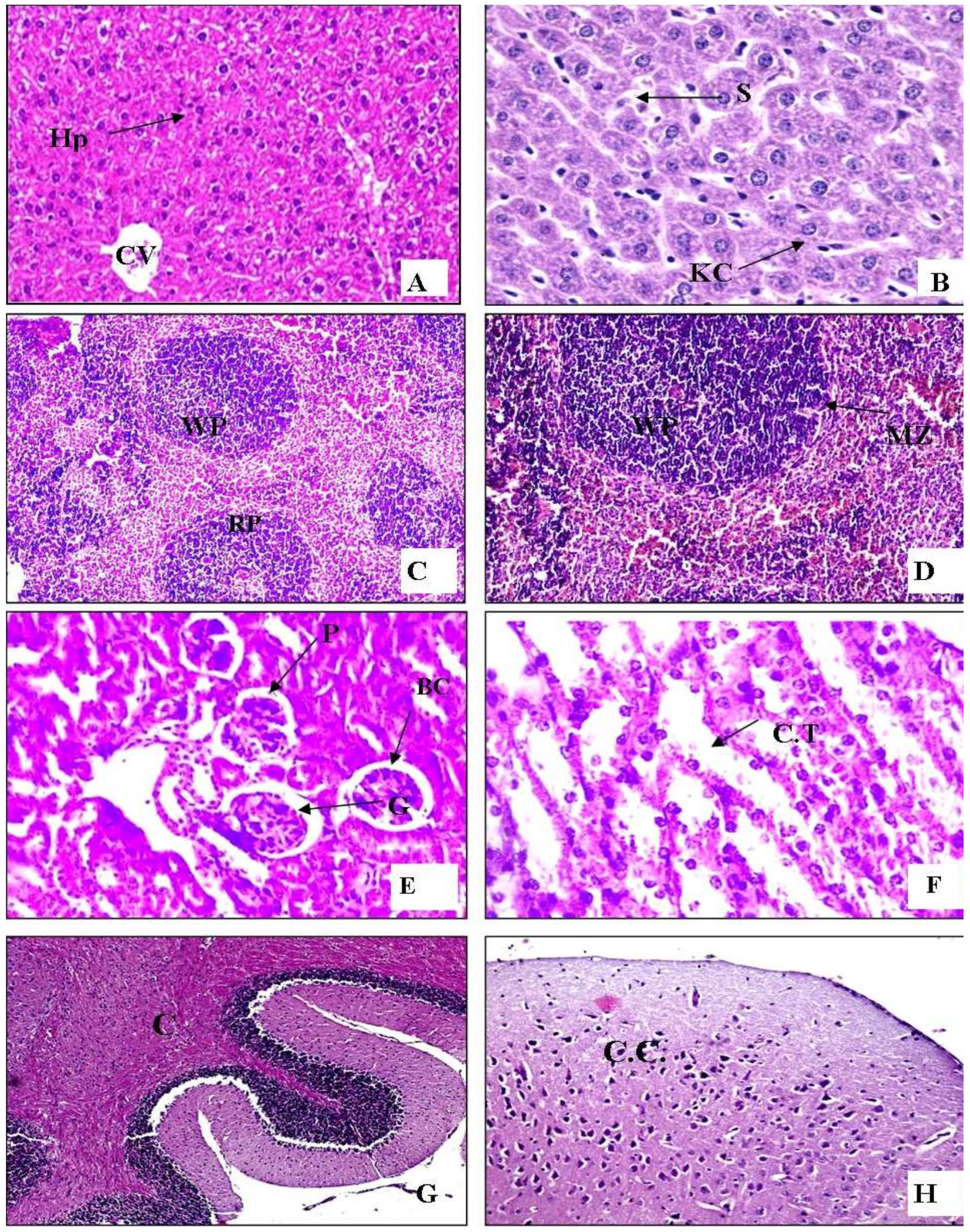

Fig. 2. Photomicrograph of liver showing (A) Normal control liver showing hepatocytes. (B) Propolis treated mice liver showing normal structure (40X) (E) Kidney of normal mice showing glomerulus (40X) (F) Propolis treated kidney of mice with normal architecture (40X) (C) Spleen with white, red pulp and marginal zone in normal mice (40X) (D) White and Red pulp in propolis treated group $(40 X)(G)$ Normal brain showing part of cerebellum $(H)$ Propolis treated normal brain showing cerebral cortex region B: Bowman's capsule, C.C: Cerebral cortex, C.V.: Central vein, C.T.: Collecting tubules, G: Glomerulus, Hp: Hepatocytes, K.C.: Kupffer cells, P: Podocytes, W.P.: White pulp, R.P.: Red pulp. 
of internal organs showed no detectable weight changes or inflammation. After exposure to a toxic substance the reduction in body weight and weight of internal organs are considered very sensitive indices of toxicity (Thanabhorn et al., 2006). According to Bindhu et al. (2007), the kidney and liver weights and histopathological changes played a crucial role in studying the sub acute oral toxicity effects of a drug. The haematopoietic system is the first and foremost target of toxic compounds and an important parameter of physiological and pathological status in animals and man (Adeneyye et al., 2006; Pan et al., 1993). After 28 days of treatment, no significant treatment related changes were observed in haematological parameters like RBC, PCV, MCV, MCHC, TLC and DLC, thus confirming that the extract was not toxic to circulating RBC's and also not interfering with the production of these cells. Lack of significant alterations were observed in propolis treated mice when compared with normal control showing normality in functions of liver and kidney. The polyphenolic compounds present in propolis (Kalia et al.,2013 and Kaur, et al., 2013b ) have protective effect for the RBC cell membrane (Youdim et al., 2000). Similar studies were performed to see the effect of different concentrations and extracts of propolis and the observations included no alterations in the serum biochemical variables like AST, LDH, triglycerides (Mani et al., 2005). Jasprica et al. (2007) studied the affect of propolis consumption on healthy individuals for 30 days on blood parameters and antioxidants. The results concluded that long term intake of propolis under desirable conditions had no significant affect on any blood parameter (Jasprica et al., 2007).

The histophatology of organs like liver, spleen, kidney and brain of control and propolis treated mice showed normal architecture. No pathological changes were observed. Similar results were seen in studies of Hollands et al. (1991) where no effect of propolis was seen in mice for 30 days. Around $1400 \mathrm{mg} / \mathrm{kg} / \mathrm{day}$ of EEP in mice was considered as NOEL ( No observed effect level).

\section{Conclusion}

The ethanolic extract of propolis did not show any toxicological manifestations in liver, spleen, kidney and brain of BALB/c mice. There were no significant treatment related changes in haematopoietic status. Hence propolis can be used in drug formulations to take the benefit of its ameliorative potential.

\section{ACKNOWLEDGEMENT}

The authors would like to thank Department of Science and Technology for assistance at various stages of this research work through INSPIRE Fellowship.

\section{REFERENCES}

Adeneya, A.A., Ajagbonna, O.P., Adeleke, T.I., Bello, S.O.
(2006). Preliminary toxicity and phytochemical studies of the stem bark aqueous extract of Musanga cecropioides in rats) Journal of Ethanopharmacology, 105: 374-379.

ArvouetGrand, A., Lejeune, B., Bastide, P., Pouraat, A. and Legret, P. (1993). Propolis extract. Part 6. Subacute toxicity and cutaneous primary irritation index. Journal de Pharmacie de Belgique, 48: 165-170.

Baker,J.R.(1945). Cytological Technique, $2^{\text {nd }}$ Ed. Metheren, London. pp 310-445.

Bindhu, M. (2007). Guidelines and a survey of current practices evaluation of organ weights for rodent and non rodent toxicity studies. A review of regulatory. Toxicologic Pathology, 35: 741-750.

Cirasino, L., Pisati, A. and Fasani F. (1987). Contact dermatitis from propolis. Contact Dermatitis, 16: 110-111.

Drago, L., Vecchi, D.E., Nicola, L., Gismondo, M.R. (2007). In vitro antimicrobial activity of a novel propolis formulation actichelated propolis). Journal of Applied Microbiology, 103: 1914-1921.

Gessler, M.C., Msuya, D.E., Nkunya, M.H., Mwasunbi, L.B., Schar, A. and Heinrich, M. (1995). Traditional healers in Tanzania: The treatment of malaria with plant remedies. Journal of Ethnopharmacology., 48: 131-144.

Ghisalberti, E.L. (1979). Propolis: a review. Bee world, 60: 59-84.

Hausen, B.M., Wollenweber, E., Senff, H. and Post, B. (1987). Propolis allergy I. Origineti Erties usage and literature review. Contact Dermatitis, 17: 163-170.

Hendi, N.K.K, Naher, H.S. and Al-Charrakh, A.H.(2011). In vitro anti-bacterial and antifungal activity of Iraqi propolis. Journal of Medicinal Plant Research, 5 (20): 5058-5066.

Hollands, I., Vidal, A., Gra, B. and Sotolongo, M. (1991). Evaluation of the sub chronic toxicity of Cuban propolis. Revista Cubana de Cliencias Veterinarias, 22: 91-100.

Jain, N.C. (1986). Hematologic technique. In: Schalm's Veterinary Hematology 4th Edition, Lea and Febiger, Philadelphia, pp 20-86.

Jasprica, I., Mornar, A., Debeljak, Z., Smolcic Bubalo C., Medic Saric,C, Mayerc, L, Romic, Z., Bucan, K., Balog, T., Sobocanec, S., Sverko, V. (2007).In vivo study of propolis supplementation effects on antioxidative status and red blood cells. Journal of Ethanopharmacology, 110: 548-554.

Kalia, P., Kumar, N.R., Harjai, K. (2013). Phytochemical screening and and antibacterial activity of different extracts of propolis. International Journal of Pharmaceutical and Biological Research, 3(6): 219-222.

Kaur, R. And Kumar, N.R. (2013 a). Pollen foraging activity of Apis mellifera during autumn season in Chandigarh. Halteres, 4:12-14.

Kaur, R., Kalia, P., Kumar, N.R. and Harjai, K. (2013 b). Preliminary studies of different extracts of some honey bee products. Journal of Applied and Natural sciences. 5(2):420-422

Mani, F., Damosceno, H.C.R., Novelli, E.L.B., Martins, E.A.M., Sforcin, J.M. (2006). Propolis: Effect of different concentration, extracts and intake period on seric biochemical variables. Journal of Ethanopharmacology. 105: 95-98.

Mirzoeva, O.K., Grishanin, R.N. and Colder, P.C. (1997). Antimicrobial action of propolis and some of its components: the effect on growth, membrane potential 
and motility of bacteria. Microbiological Research, 152: 239-246.

Monti, M., Berti, E., Carminati, G. and Cusini, M. (1983). Occupaional and cosmetic dermatitis from propolis. Contact dermatitis, 9:163.

OECD. (2002)Guidelines for the Testing of Chemicals/ Section 4: Health Effects Test No. 423: Acute Oral toxicity - Acute Toxic Class Method. Organization for Economic Cooperation and Development, Paris, France.

OECD. (2008) Repeated dose oral toxicity test method. In: OECD Guidelines for teting of chemicals, $N^{\circ} 407$. Organization for Economic Cooperation and Development, Paris, France

Pan, Y.T., Ghidoni, J. and Elbein, A.D. (1993). The effects of castanospermine and swainsonine on the activity and synthesis of intestinal sucrose. Archives of Biochemistry and Biophysics, 303: 134-144.

Singla, S., Kumar, N.R. and Kaur, J. (2014). In vivo Studies on the protective effect of propolis on doxorubicin induced toxicity in liver of male rats. Toxicology International, 21(2): 191-195.

Thanabhorn, S., Jenjoy, K., Thamaree, S., Ingkaninan, K. and Panthong, A. (2006). Acute and subacute toxicity study of the ethanol extract from Lonicera japonica. Thunb. Journal of Ethanopharmacology, 107: 370-373.

WHO.(2000) General guidelines for methodologies on research and evaluation of traditional medicine. WHO Geneva.

Youdim, K.A., Shukitt-Hale, B., MacKinnon, S., Kalt, W. and Joseph, J.A. (2000). Polyphenolics enhance red blood cell resistance to oxidative stress: in vitro and in vivo. Biochimica et Biophysica Acta, 1523: 117-122. 